\title{
Does the Customer Know Best? The Results of a Survey on E-Commerce Development
}

\author{
Julian Terry \\ School of Computer and Information Science, \\ Edith Cowan University, Perth, Australia
}

\author{
j.terry@ecu.edu.au
}

\begin{abstract}
This study surveys forty four project leaders of recently completed e-commerce sites regarding customer participation in e-commerce development activities. Throughout the literat ure for four decades, a commonly cited factor pertaining to system success has been user participation in the systems development process. The business need for a rewarding customer experience on an ecommerce site would suggest customer input would substantially influence the site design. The study finds that participation by customers in developmental activities is occurring, but at a less than anticipated rate and resulting in little influence on the design of the site.
\end{abstract}

Ke ywords: User participation, project management, electronic commerce, systems development

\section{Introduction}

Since the 1960's it has been generally acknowledged that user participation in the Information Systems (IS) development process increases the likelihood of project success (Barki \& Hart wick, 1994; Foster \& Franz, 1999). Put another way, lack of communication between users and developers has been a common theme in the well-documented reasons for failures in IS implementations (Bussen \& Myers, 1997). User involvement is likely to result in increased user satisfaction (Garceau, Jancura, \& Kneiss, 1993), and the perceived usefulness of the application (Foster \& Franz, 1999; Franz \& Robey, 1986; McKeen, Guimaraes, \& Wetherbe, 1994). Foster and Franz (1999) emphasise the need for user involvement, most import antly in the early stages of development, concluding, "managers should actively seek user involvement in systems development activities" (p.345).

The portfolio of applications being developed today has changed with the emergence of the ECommerce (EC) business paradigm. Organisations are capitalising on the potential of new technologies such as the Internet, Intranets and the World Wide Web to improve communications and

Material published as part of this publication, either on-line or in print, is copyrighted by the Informing Science Institute. Permission to make digital or paper copy of part or all of these works for personal or classroomuse is granted without fee provided that the copies are not made or distributed for profit or commercial advantage AND that copies 1 ) bear this notice in full and 2) give the full citation on the first page. It is permissible to abstract these works solong as credit is given. To copy in all other cases or to republish or to post on a serveror to redistribute to lists requires specific permission and payment of a fee. Contact Publisher@ InformingScience.org to request redistribution permission. transaction efficiency, reduce operation costs and increase market share. This paradigm shift in business has been supported by applications with a different focus. While organizations cont inue to implement IS for internal use and to integrate with known business partners, the focus of this paper is business-tocustomer (B2C) applications that are available for universal use. 
The literature to date regarding user participation in IS development has not differentiated between applications designed for traditional environments or for B2C. In comparing the two domains, Fraternali (1999) states:

"Applications for the Internet in such domains as electronic commerce, digital libraries and distance learning are characterized by an unprecedented mix of features that makes them radically different from previous applications of information technology" (p. 227).

However the underlying process for developing applications is addressed by Yourdon (2000), who questions whether e-business/Internet projects are really that different by suggesting "Ebusiness projects face the same demands pressures and risks as any other kind of IT development project, but to a greater degree". This added pressure comes from not only squeezed timeframes for delivery, but also from the necessity to change accompanying business processes. He suggests also that "the e-business phenomenon is much more fundamental because it creates a much more intimate connection with customers, vendors and suppliers".

One feat ure of B2C systems that differentiates them from traditional MIS applications is the identity of the "user". Traditional systems are developed for a clearly defined set of known users either in-house or business partners. The development may be undertaken in-house or by external parties, but either way, the user communities are clearly identifiable. They are often championing the project and possibly funding it from their budget. Likewise off-the-shelf packages allow organisations to see what they are getting before soft ware purchase. Customisation of the package to meet the organisations needs can then precede implementation. Again the known, distinguishable in-house user community is able to be involved in decisions regarding the adoption and adaptation of the product.

In the global business environment of today, a B2C application is inviting the consideration of the world at large. Rather than serving a known user group, B2C sites may target the world at large. Potential users are diverse in all respects, ethnically, culturally as well as geographically. They are also diverse in their computing skills as noted by Fraternali (1999),

"Universal access by individuals with limited or no skills in the use of computer applications introduces the need of new man-machine interfaces capable of capturing the customer's attention and facilitating access to information" (p.227).

The ability to have representative end-user participation in B2C IS development is radically different from obtaining user involvement in traditional systems. The question is "are potential B2C end-users being included in the development process?" Terry and Standing (2001) in a series of preliminary interviews with five project leaders reported that "despitethe business need for remote, untrained users to quickly feel comfortable and satisfied in an e-commerce site encounter, it appears that organisations are making very little effort to engage users in any e-commerce site developmental activities" (p. 671).

This paper investigates the extent of user participation in B2C IS developments by surveying project leaders of substantial B2C developments. Forty-four leaders of recently completed projects, were questioned on the role of users throughout the development lifecycle, along with the contingency factors of resource constraints and system impact that may affect the commitment of the organisation to the success of the system. The results are presented.

\section{Users and User Involvement}

The term "user" is open to ambiguity. Land and Hirschheim (1983) acknowledge the existence of different types of user: senior management who bear ultimate responsibility for the organisation's 
well-being and who may use outputs of IS developments; middle management who are responsible for the operational staff using the IS, and finally those staff who regularly interact with the system. From project conception, through the development lifecycle each of these users may contribute or participate in IS development activities. The term "user" is not generally defined specifically in the many studies published in literature, beyond the Ives and Olson (1984) definition of them as "representatives of the target user group" (p. 587).

User involvement has traditionally been referred to as participation in the system development process measured as a set of activities that users or their representatives have performed (Baroudi, Olson, \& Ives, 1986; Doll \& T orkzadeh, 1989; Ives \& Olsen, 1984). Barki and Hart wick (1994) proposed a clearer definition for user involvement, distinguishing it from user participation as in other disciplines. They define user participation as a "the assignments, activities and behaviours that users or their representatives perform during the systems development process" (p. 60). User involvement refers to the "subjective psychological state reflecting the importance and personal relevance that a user attaches to a given system" (p. 60). These definitions appear to have been generally accepted in the en suing literat ure (Hunton \& Beeler, 1997; McKeen \& Guimaraes, 1997) as they are in this paper.

The literature has not found the ident ity of the users or their representatives to be a contentious point. Often all of the three user types above are domiciled in the same workplace and are identifiable to IS development project managers. Their participation in for example, problem definition, specification of requirements, design and testing could be mandated within the organisation. So the users involved in IS projects are clearly identifiable to pract itioners and to researchers.

Identifying the user community in B2C systems development is more difficult. The three user types identified by Land and Hirschheim (1983) still exist. Senior management involvement in the conceptualisation of a system is particularly import ant given the structural business change that will need to accompany the introduction of EC. While middle management is not as prevalent in the workforce, this group covers expert users who will have essential input developing requirements and design. Organisations will also have operational staff interacting with the system. However another user type has emerged. B2C transactions involve remote customers who may not be known to the organisation. They are the ultimate end-users, but are beyond the accepted definition of users above. They are not staff and do not fall under the control structures of the organisation. Business success is base d on their acceptance and usage of the system. However their participation cannot be mandated. Likewise their involvement or attitudinal disposition to the system. We will call this group of users "customer-users".

\section{System Success}

While there is no direct measure for the success of an Information System, (see DeLone \& McLean, 1992), empirical researchers have commonly used user satisfaction as the dependent variable (Doll \& Torkzadeh, 1990; Franz \& Robey, 1986; McKeen \& Guimaraes, 1997; Powers $\&$ Dickson, 1973). Prominent among the independent variables studied for their influence on this measure, are user involvement or participation in the system development process.

Although the efficacy of user involvement in information systems development leading to system success has been the subject of much research, it has not been studied in the context of B2C systems development. However, the concept of system success as measured by user satisfaction may be more relevant to B2C developments than to traditional systems. Ensuring a system is successful from a user perspective is related to: 


\section{Meeting Requirements}

For a system to be useful to users it should provide appropriate functionality. This may include providing relevant information, entertainment, downloads, or transaction capabilities.

\section{Usability}

There are many aspects of information systems design that impact on usability including: the design of the user interface, ease of navigation, online and offline help, system performance and error handling (Fisher, 1999). With no compulsion to visit and interact with a site, an Internet user needs to feel comfortable with a site's usability - and quickly. If not they can and do take their trade to another site. Shopping cart abandonment rates of 20 to 60 percent per transaction reported by Schwarz (2001) are testament to dissatisfied customers.

It has been said that there is only one chance to make a first impression. In the Internet world it may be better to have no site than an unintuitive one that is unlikely to be revisited. Furthermore customer-users are not availed of the training in application use that traditional system users expect. User support is also not likely to be as readily available. So there is a need for EC developers to be particularly sensitive to usability issues.

\section{Research Methodology}

The relationship between customer participation in EC system development and system success, as perceived by the customer is the central focus of this paper. This relationship has been ignored in the academic literature to date; it is beyond the scope of the generally accepted definition of "user participation". This paper forms part of a wider study seeking a view of this relationship from several perspectives - the project leader, the business sponsor, internal system users and external customers. This paper presents the perspective of 44 project leaders.

Project leaders of recently completed EC developments or substantial redevelopments were interviewed to ascertain the extent if any of customer profiling and customer participation in development activities. They have been responsible for the development of the EC application and are able to respond to questions regarding customer participation in the developmental process. They were asked multi-dimensional questions pertaining to potential areas for inclusion of user input throughout the development process, namely:

- requirements gathering,

- design,

- usability testing,

- post-implementation review

The other perspectives relating to the same EC system are being simultaneously capt ured but not yet analysed. The business sponsor is surveyed regarding costs and strategic, transactional, informational and general benefits. Internal users are asked about their participation in the EC development - they are the current equivalent of the user of traditional MIS developments. Customers are evaluating the EC sites in terms of usability, information quality, and the feeling of a sense of relationship with the organisation.

\section{Results}

The section describes an initial reporting and interpretation of the survey data as a precursor to a detailed quant it ative analy sis. 
Table 1 shows a summary of the data. Project leaders were asked a number of questions relating to cust omer participation in Requirements, Design and User Testing based on a 5 point Lickert scale. The figures shown here are an aggregation of these multiple questions in each area.

The customer perception of the success of the site was a rounded average of the perceptions of five customers of each site.

Table 1: Project leader perspe ctive of user participation.

\begin{tabular}{|l|l|l|l|l|l|l|l|l|l|l|l|l|l|l|l|}
\hline Organisation \# & $\mathbf{1}$ & $\mathbf{2}$ & $\mathbf{3}$ & $\mathbf{4}$ & $\mathbf{5}$ & $\mathbf{6}$ & $\mathbf{7}$ & $\mathbf{8}$ & $\mathbf{9}$ & $\mathbf{1 0}$ & $\mathbf{1 1}$ & $\mathbf{1 2}$ & $\mathbf{1 3}$ & $\mathbf{1 4}$ & $\mathbf{1 5}$ \\
\hline Requirements & 1 & 5 & 1 & 3 & 4 & 3 & 4 & 1 & 5 & 4 & 4 & 3 & 1 & 4 & 4 \\
\hline Influence & 1 & 3 & 1 & 1 & 5 & 4 & 4 & 1 & 3 & 4 & 4 & 4 & 1 & 5 & 3 \\
\hline Design & 1 & 4 & 1 & 1 & 5 & 3 & 3 & 1 & 3 & 1 & 1 & 2 & 1 & 2 & 1 \\
\hline Usability testing & 1 & 2 & 1 & 1 & 3 & 4 & 5 & 1 & 5 & 4 & 2 & 4 & 4 & 2 & 1 \\
\hline
\end{tabular}

\begin{tabular}{|l|l|l|l|l|l|l|l|l|l|l|l|l|l|l|l|}
\hline Organisation \# & $\mathbf{1 6}$ & $\mathbf{1 7}$ & $\mathbf{1 8}$ & $\mathbf{1 9}$ & $\mathbf{2 0}$ & $\mathbf{2 1}$ & $\mathbf{2 2}$ & $\mathbf{2 3}$ & $\mathbf{2 4}$ & $\mathbf{2 5}$ & $\mathbf{2 6}$ & $\mathbf{2 7}$ & $\mathbf{2 8}$ & $\mathbf{2 9}$ & $\mathbf{3 0}$ \\
\hline Requirements & 2 & 3 & 3 & 2 & 4 & 1 & 3 & 5 & 4 & 3 & 1 & 1 & 2 & 2 & 3 \\
\hline Influence & 3 & 1 & 1 & 2 & 3 & 1 & 3 & 3 & 4 & 4 & 1 & 1 & 1 & 1 & 1 \\
\hline Design & 1 & 2 & 1 & 2 & 2 & 1 & 1 & 2 & 2 & 1 & 1 & 1 & 1 & 2 & 1 \\
\hline Usability testing & 2 & 3 & 1 & 3 & 3 & 2 & 1 & 2 & 4 & 4 & 1 & 1 & 1 & 1 & 1 \\
\hline
\end{tabular}

\begin{tabular}{|l|l|l|l|l|l|l|l|l|l|l|l|l|l|l|}
\hline Organisation \# & $\mathbf{3 1}$ & $\mathbf{3 2}$ & $\mathbf{3 3}$ & $\mathbf{3 4}$ & $\mathbf{3 5}$ & $\mathbf{3 6}$ & $\mathbf{3 7}$ & $\mathbf{3 8}$ & $\mathbf{3 9}$ & $\mathbf{4 0}$ & $\mathbf{4 1}$ & $\mathbf{4 2}$ & $\mathbf{4 3}$ & $\mathbf{4 4}$ \\
\hline Requirements & 5 & 1 & 4 & 4 & 3 & 1 & 2 & 3 & 3 & 3 & 2 & 1 & 2 & 1 \\
\hline Influence & 4 & 1 & 4 & 4 & 5 & 1 & 3 & 3 & 4 & 4 & 3 & 1 & 2 & 1 \\
\hline Design & 2 & 1 & 4 & 4 & 5 & 1 & 2 & 2 & 1 & 2 & 2 & 1 & 1 & 1 \\
\hline Usability testing & 4 & 1 & 3 & 4 & 4 & 1 & 2 & 3 & 1 & 4 & 2 & 1 & 2 & 1 \\
\hline
\end{tabular}

Requirements, Design and Usability testing are based on a 5 point Lickert scale for customer input where: $1=$ no input, to $5=$ extensive input.

Influence uses a 5 point Lickert scale where:

$1=$ customer input had no influence on site requirements, to $5=$ customer input had extensive influence on site requirements. 


\section{Requirements Gathering}

Seventy-five percent of respondents incorporated some form of user participation in the Requirements gathering process. Many used more than one technique. Of these $75 \%$, the techniques most used to elicit requirements were:

- evaluation of comparable sites (64\%)

- electronic (email or web-based) surveys (57\%),

- bringing people together for focus groups (45\%),

- conducting telephone surveys (33\%),

- interviews (33\%).

- traditional paper-based surveys $(21 \%)$

It appears that project leaders employ a wide variety of techniques to capture information regarding "what" potential customers would like the site to provide. Seventy eight percent of the organisations that embraced user participation utilised 3 to 6 different techniques in the requirements gathering process (see Figure 1).

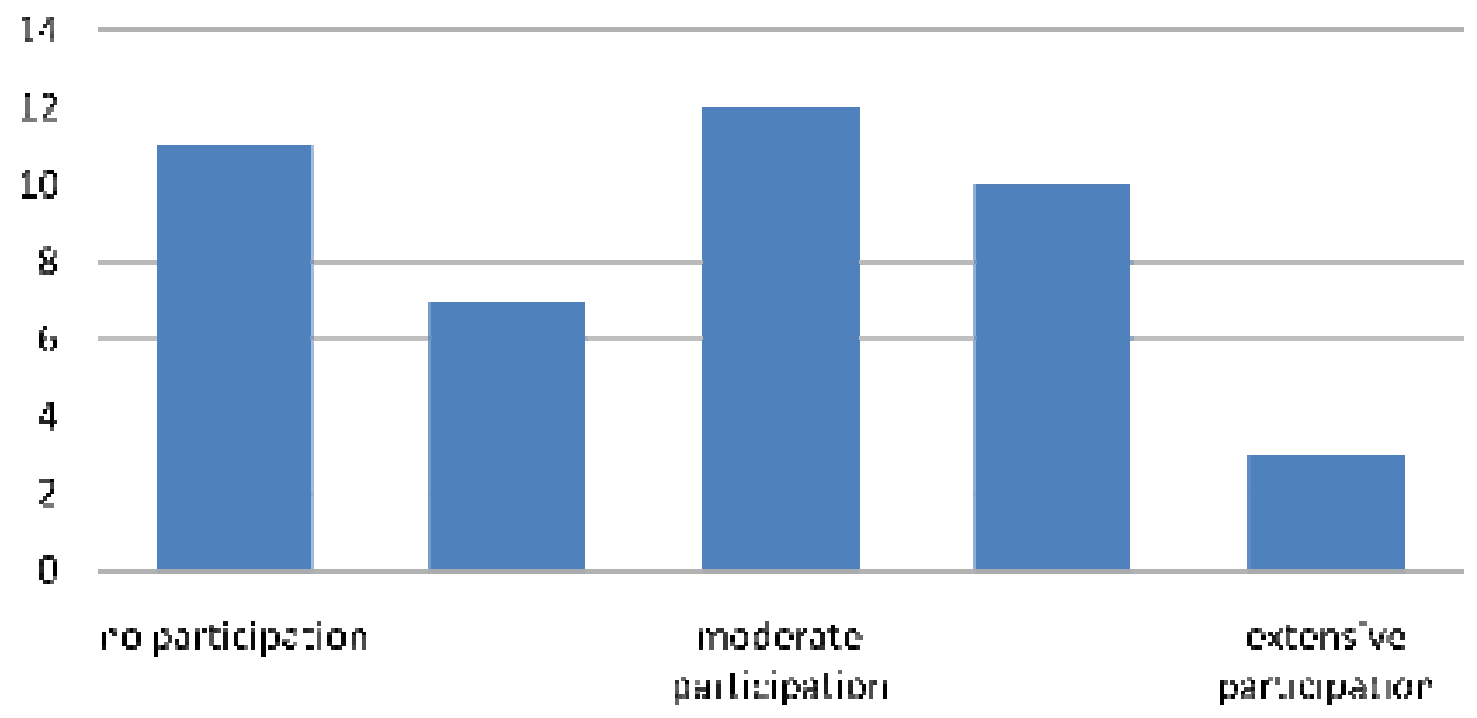

- Cigure 1: C.stomer participation in requiren"ents analysis

Participation in a process and influence brought to bear on a final product may be quite different. From the above results it appears that the respondent project leaders were keen to utilise potential users. However project leaders were also asked the question, "to what extent did the input from target ed customers influence the content of the site?" Twenty one percent of the organisations that embraced some form of user participation indicated that the influence of the targeted customers on the site was zero (see Figure 2). These organisations with project leaders that involved customers in determining requirements for their site, were unable to utilise any customer input into the site requirements. Together, the organisations not utilising customers in requirements and those not being influenced by them account for $43 \%$ of the sample. Only three project leaders $(9 \%)$ indicated that the user participation led to extensive influence on the content of the site. 


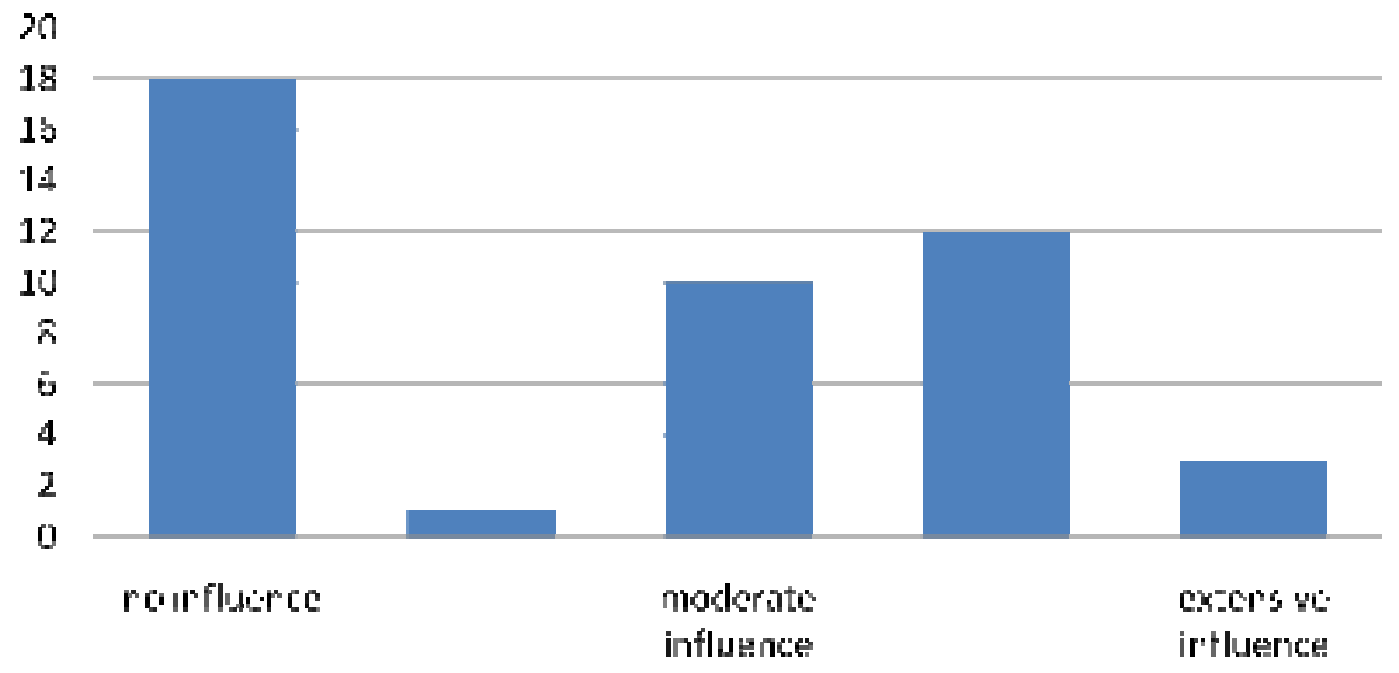

Figure 2. 6. astomer influpnse ren lequiremerts

\section{Design}

There was a significant fall away of customer participation from requirements gathering to design activities. Forty eight percent of all organisations, (or only $61 \%$ of organisations that used customers for requirements gathering), utilised customers for design activities (see Figure 3). Of this group the activities and participation rates were as follows:

- a walkthrough of the completed design (45\%);

- developing the structure of the site $(15 \%)$, and

- developing the navigation for the site (15\%).

Therefore the major design activity in which the project leaders invited customer resources for input, was to provide feedback after the design had been completed; this exceeded customer involvement in developing the design.

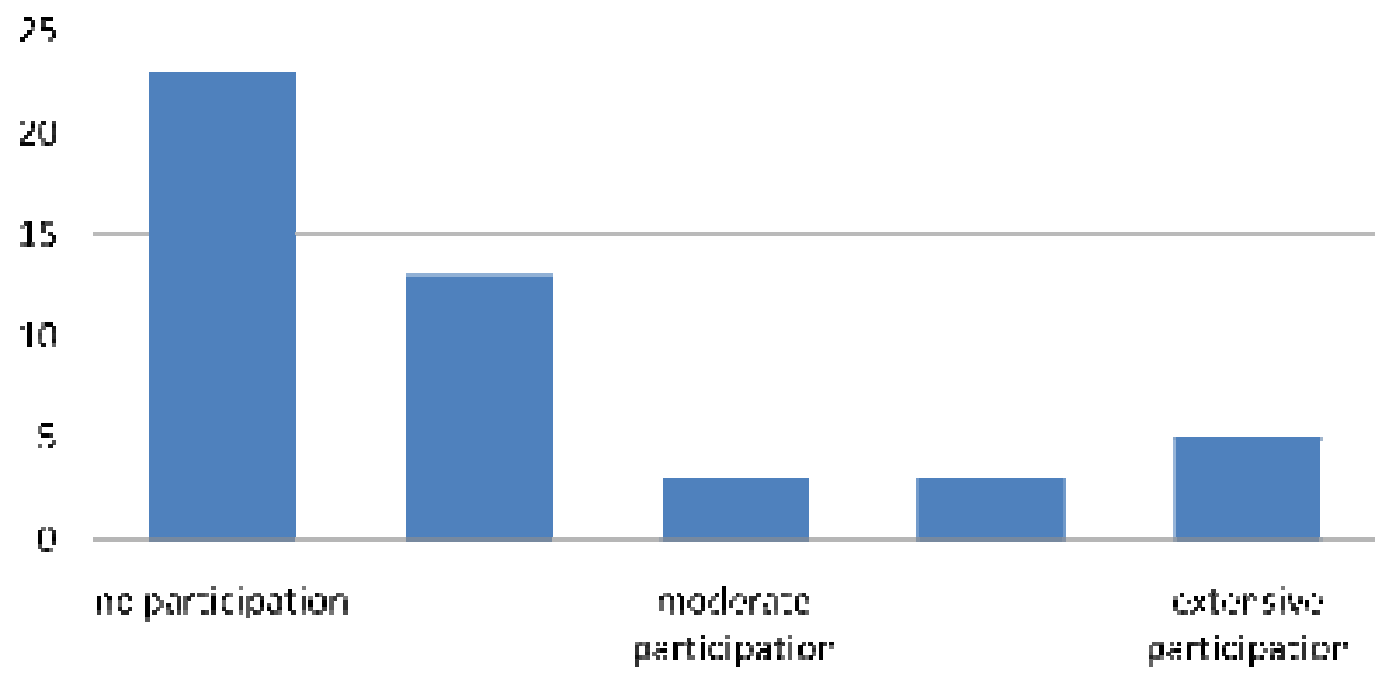

تig.Je 3: C.uttomer par-iriationin Jesigr 


\section{Usability Testing}

Sixty one percent of project managers had potential customers perform some form of usability testing on the site (see Figure 4). Those organisations that performed usability testing employed a variety of testing techniques as are shown below:

- The customers were given specific tasks to perform (37\%),

- The customers were asked to complete a questionnaire regarding their experiences (30\%),

- The customers were observed while performing usability testing (26\%),

- The customers' actions were aut omatically logged as they performed tests (22\%),

- The customers were asked to verbalise their thoughts as they performed tests (22\%),

- The customers were recorded while performing usability testing, for later analysis (7\%).

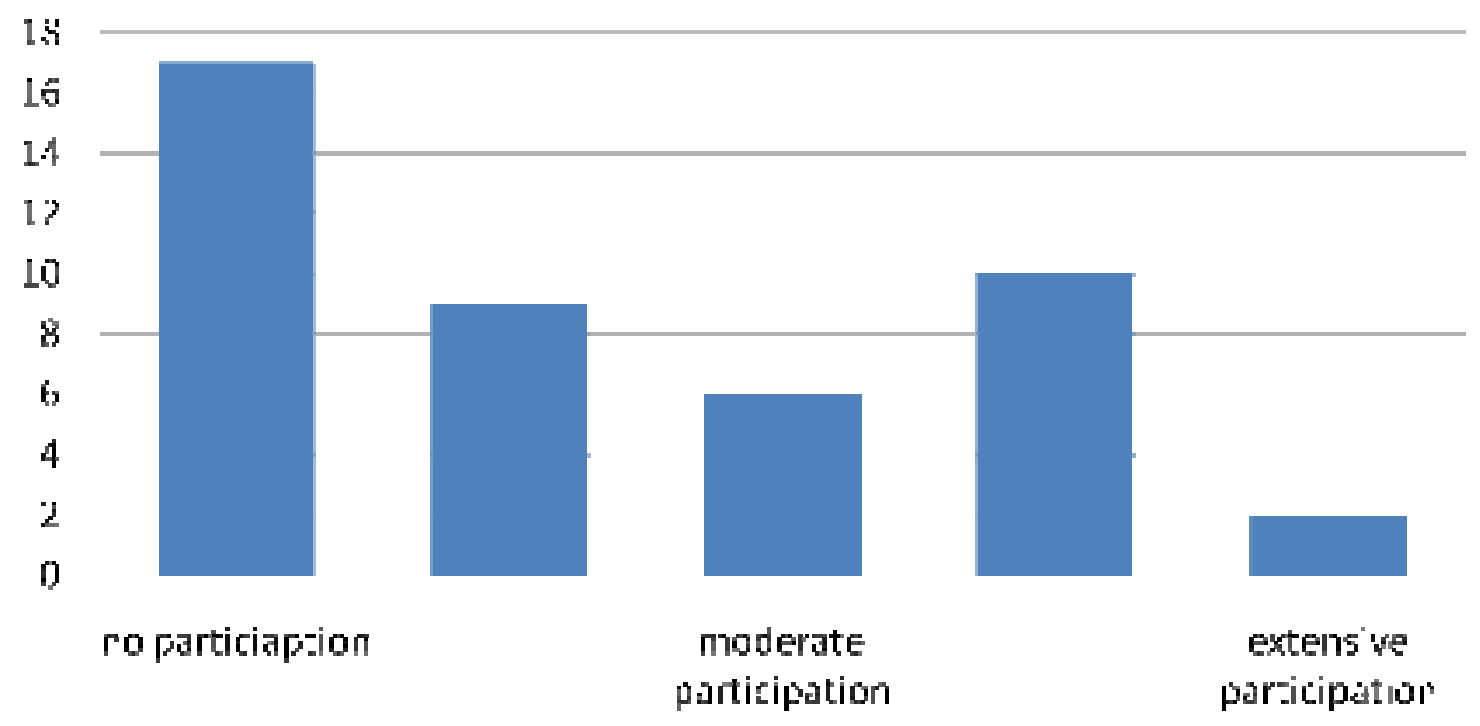

Figure 4 : Custorer participotionin usability zesing

\section{Metrics from Testing}

Of the organisations that performed usability testing, $78 \%$ collected quantitative performance measurements from the process. The following are metrics were collected with numbers as percentage of all organisations:

- Tasks successfully completed (34\%),

- Number of errors made (23\%),

- Time taken to complete a task (20\%),

- Time spent recovering from errors $(9 \%)$.

\section{Beta testing}

Fifty percent of organisations released the application to a limited set of customers for bet a testing before putting the application into full production. All of these organisations had involved customers in usability testing. 


\section{Post-implementation review}

There was very little active seeking of site review feedback from customers. Only $23 \%$ of all organisations asked customers to complete either an online or paper-based survey. None used a commercially or generally available instrument for this purpose. However $61 \%$ of organisations indicated that they perform their own review of customer/site interaction by evaluating site logs. The majority of organisations $(73 \%)$ provided a passive mechanism for some form of customer feedback - this was a simply providing a link for customers to cont act the webmaster concerning problems or suggestions.

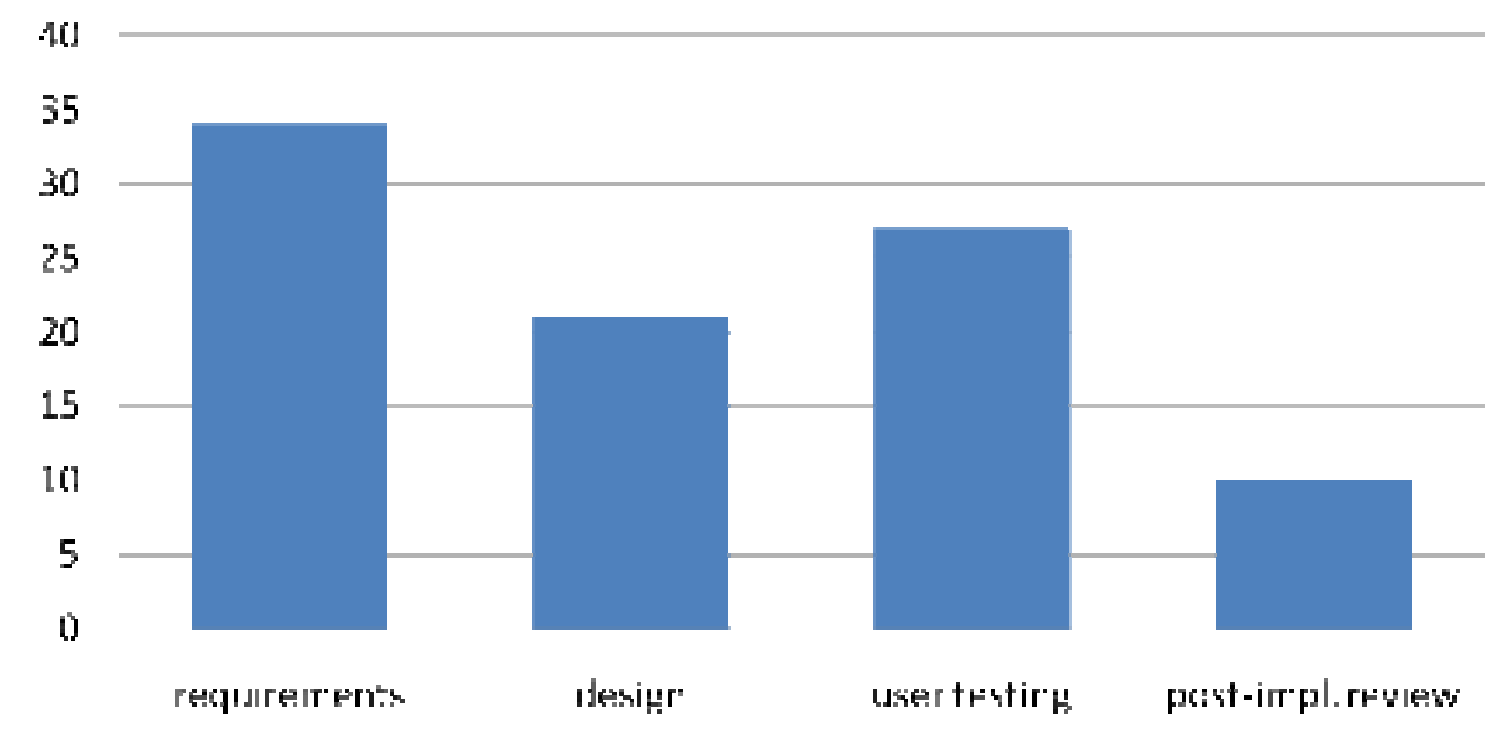

Figure 5: User participation in devalopment activities

\section{Discussion}

This paper describes the perspective of project leaders of EC developments, regarding customer participation in projects. The majority of projects $(75 \%)$ have embraced some form of customer participation in the development process (See Figure 5). The scale of this participation has varied markedly between development phases. There was a clear drop in participation in design phase activities, but all projects that utilised user participation in design had also done so in the requirements analysis phase. In fact of the 34 projects that used customers in requirements generation, only 9 continued to use them in developing the design (as opposed to a customer walkthrough of the design, which a further 11 projects utilised).

Only one further organisation emerged to involve customers in user test ing activities, (including both usability and beta testing), that had not done so in requirements analysis.

While it is unclear why there is a drop away in user participation afterthe requirements gathering exercise, the influence these customers exerted on the final site requirements emerges as an interesting statistic. Of the 34 projects that used customers for requirements gathering, 7 (21\%) indicated that the customer input had no influence on the site at all, and only 3 of these 34 organisations $(9 \%)$ had extensive influence. It would appear that these project leaders found customers did not add significantly to the requirements of the system. Either the customers espoused what was already known by the organisation about the site requirements, or their input was discarded as being outside the project scope. It is realistic to conclude that many organisations attempting to transact with customers over the web do have a clear idea of what their site is going to provide. In 
many cases content and functionality for a limited product set is restricted. Navigation is likewise. As the web becomes more accepted as a means of completing commercial transactions, EC site developers and consumers alike have more shared expectations about site usability. The mostperformed requirements gathering function by customers, was the evaluation of comparable sites.

This paper summarises the complete data set collected from project leaders. However it is only part of a multi-perspective study that has also surveyed business sponsors, internal users and the actual customers of the site. Of interest will be the comparative dat a on the success of the EC site and any links to the role of the customer in the developmental activities. This preliminary summary analysis indicates that project leaders are not utilising customers in development act ivities to the extent that was anticipated. There could be any number of reasons why this is so:

- project leaders believe the customers do not know what is required or how it should be designed,

- developers are getting better at understanding the requirements for EC systems, many of which have basic features in common,

- EC development teams include design specialists who substitute for the customer.

\section{Conclusion}

This research has been motivated by the need for a comprehensive study addressing the relationship between system success and user participation in modern systems development. This paper represents an initial analysis of the first part of that study - the project leader perspective of customer participation throughout development.

The generally accepted traditional view that user participation is essential in Information Systems developmental activities is not seen to be particularly relevant to EC developers. Nearly half of all organisations ( $43 \%$ ) either did not involve customers in requirements or were not influenced by their input. End-user input to requirements is either not augmenting what the organisation already knows about the site content and functionality, or is being discarded for reasons that may include it being out side of desired scope. The major activity that customers provided input to in the design phase was a walk-through of the design prototype; in other words providing feedback after a preliminary design had already been done. A developmental phase specifically designated for user participation, usability testing had a participation rate of only $61 \%$ of organisations, with beta testing down to $50 \%$. Post-implement at ion review relied more on passively providing a link for interested customers to make comment (73\%), than actively seeking their input (23\%). It appears that despite the necessity of customers being positive about the EC experience for its survival, their involvement by project leaders is not seen to be particularly important. It may be that developers of EC systems are in fact users themselves and see themselves as such, therefore the need to involve "outsiders" is lessened. Also these developments are seen as more evolutionary in nat ure with shorter than traditional time frames for upgrades after the system has been implemented.

Myers et al (1996) state that "users expect highly efficient and easy-to-learn interfaces and developers now realize the crucial role the interface plays" (p. 794). The isolation of the user from the developer in EC and the proliferation of EC in Australian society may have blurred the once clear roles of user as specifier, and IT professional as developer of systems. 


\section{References}

Barki, H., \& Hartwick, J. (1994). Rethinking the concept of user involvement, and user attitude. MIS Quarterly, 18(1), 59-79.

Baroudi, J. J., Olson, M. H., \& Ives, B. (1986). An empirical study of the impact of user involvement on system usage and information satisfaction. Communications of the ACM, 29(3), 232-238.

Bussen, W. S., \& Myers, M. D. (1997). Executive information systems failure: A New Zealand cas e study. PACIS '97, Brisbane, Information Systems Management Research Concentration, Queensland University of Technology, Australia.

Cavaye, A. L. M. (1995). User participation in system development revisited. Information and Management, 28(5), 311-323.

DeLone, W. H. \& McLean, E. R. (1992). Inform ation systems success: The quest for the dependent variable. Information Systems Research, 3(1), 60-95.

Doll, W. J., \& Torkzadeh, G. (1989). A discrepancy model of end-user computing involvement. Management Science, 35(10), 1151-1171.

Fisher, J. (1999). Improving the usability of information systems: The role of the technical communicator. European Journal of Information Systems, 8, 294-303.

Foster, S. T., Jr., \& Franz, C. R. (1999). User involvement during information systems development: A comparison of an alyst and user perceptions of system accept ance. Journal of Engineering and Technology Management, 16, 329-348.

Franz, C. R., \& Robey, D. (1986). Organisational context, user involvement, and the usefulness of in formation systems. Decision Sciences, 17(3), 329-356.

Fraternali, P. (1999). Tools and approaches for developing data-intensive web applications: A survey. ACM Computing Surveys, 31(3), 227-263.

Garceau, L., Jancura, E., \& Kneiss, J. (1993). Object oriented analysis and design: A new approach to systems development. Journal of Systems Management, 44, 25-33.

Howcroft, D., \& Carroll, J. (2000). A proposed methodology for web development. Proceedings of the European Conference on Information Systems, Vienna, 290-297.

Hunton, J. E., \& Beeler, J. D. (1997). Effects of user participation in systems development: A longitudinal experiment. MIS Quarterly, December, 359-383.

Ives, B., \& Olsen, M. H. (1984). User involvement and MIS research: A review of research. Management Science, 30(5), 586-603.

Land, F., \& Hirschheim, R. (1983). Participative systems design: Rationale, tools and techniques. Journal of Applied Systems Analysis, 10, 91-107.

Mirani, R., \& Lederer, A. L. (1998). An instrument for assessing the organizational benefits of IS projects. Decision Sciences, 29(4), 803-838.

McKeen, J. D., \& Guimarares, T. (1997). Success ful strategies for user participation in systems development. Journal of Management Information systems, 14(2), 133-150.

McKeen, J. D., Guimaraes, T., \& Wetherbe, J. C. (1994). The relationship between user participation and user satisfaction: An investigation of four contingency factors. MIS Quarterly, December, 427-451.

Myers, B., Hollan, J., Cruz, I., Bryson, S., Bulterman, D., Catarci, T., et al. (1996). Strategic directions in human-computer interaction. ACM Computing Surveys, 28(4), 794-809.

Powers, R. F., \& Dickson, G. W. (1973). MIS project management: Myths, opinions and reality. California Management Review, 15(3), 147-156.

Schwarz, M. (2001). The care and keeping of online customers. Information Age, Feb-Mar, 61-62. 
Silverman, D. (2000). Doing qualitative research. A practical handbook. London: Sage Publications.

Terry, J. E., \& Standing, C. (2001). User involvement in e-commerce systems development. Proceedings of the Twelfth Australasian Conference on Information Systems, Coffs Harbour, 671-678.

Yin, R. (1994). Case study research; Design and methods (2nd ed.). Sage.

Yourdon, E. (2000). Success in e-projects. Computerworld, August 21.

\section{Biography}

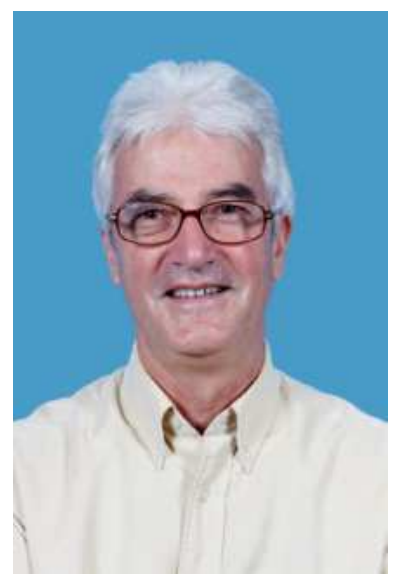

Julian Terry is a lecturer is Computer Science at Edith Cowan University in Perth, Australia. He is currently completing his PhD on software development methodologies for e-commerce systems. He teaches in Soft ware Engineering and has published in the Australian Computer Journal and the International Journal of e-Business Management. 